\title{
ТЕОРИЯ И ПРИКЛАДНЫЕ ФОРМАТЫ АУКЦИОНОВ: КРАТКИЙ ОБЗОР
}

\section{В.А. Воробьев, И.В. Жабенок}

Представлен вклад П. Милгрома и Р. Уилсона в экономическую теорию аукционов. Дан обзор основных теоретических моделей аукционов, особое внимание обращается на теорему об эквивалентности доходов и эффект «проклятия победителя». Раскрыт спектр проблем и достижений, связанных с разработкой новых форматов аукционов и их практическим использованием.

Ключевые слова: аукцион, модель с частными ценностями, модель с общими ценностями, модель с частными и общими ценностями, одновременный многораундовый аукцион, комбинаторный аукцион, стимулирующий аукцион.

JEL-классификация: B21, D44, D47.

DOI: $10.46782 / 1818-4510-2020-4-4-19$

Материал поступил 17.11.2020 2.

\section{I. Теория аукционов}

Аукционы как область рыночного дизайна. Децентрализованные решения разрозненных экономических агентов, взаимодействующих на рынке, являются эффективными, если основаны на информации и стимулах, правильно отражающих общественные предпочтения (например, когда все субъекты рынка сталкиваются с ценами, на которые не могут повлиять). Такая ситуация характерна для многих видов экономической деятельности, но далека от универсальности. Последнее объясняется провалами рынка - существованием неполной и асимметричной информации, монопольной власти, внешних эффектов, общественных благ. Имеется потребность в разработке механизмов, которые могли бы устранять последствия неудач рынка.

Теоретическое осмысление проблем неполной информации и несовершенной конкуренции невозможно без анализа стратегического взаимодействия экономических субъектов на основе теоретико-игрового подхода. Неоклассической экономической теории долгое время удавалось обходиться без него, постулируя совершенную конкуренцию, когда выбор потребителей и производителей превращается в решение простой задачи максимизации. Но поскольку совершенная конкуренция в чистом виде нереалистичное предположение, постольку теория игр становится аналитическим инструментом, важным для понимания работы экономической системы (Harsanyi, 1995). И к концу 1970-х гг. теоретико-игровой подход получил широкое распространение в качестве основного инструмента моделирования и анализа в теоретической микроэкономике (Roth, Wilson, 2019). При разработке механизмов взаимодействия экономических субъектов с учетом эффектов стратегического поведения акцент в исследованиях сделан на проблеме несовершенной информации: во-первых, она первична, поскольку сама по себе порождает рыночную власть; во-вторых, при совершенной информации процесс обмена может быть спроектирован так, чтобы устранить рыночную власть (Wilson, 1985).

* Воробьев Виктор Анатольевич (vorobiev_v@bseu.by), доктор экономических наук, профессор, Белорусский государственный экономический университет (г. Минск, Беларусь);

Жабенок Игорь Валентинович (ihar.zhabianok@gmail.com), кандидат экономических наук, доцент, Белорусский государственный экономический университет (г. Минск, Беларусь). 
Подходящими объектами для приложения теории игр являются аукционы, которые четко фиксируют «правила игры», представляют собой простой и наиболее известный способ определения цен в отсутствие посредников. В последние шестьдесят лет наблюдается значительный практический, эмпирический и теоретический интерес к данной форме рыночного дизайна (Klemperer, 1999) 1 .

Во-первых, аукционы идеально подходят для любой отрасли, где необходимо продавать или покупать несколько предметов в малых или больших количествах. Правительство использует торги для продажи государственных ценных бумаг, прав пользования недрами. Государственные контракты обычно заключаются на аукционах по закупкам. Металлы, химические вещества, продукция сельского хозяйства и рыболовства, нефть и газ, мощности трубопроводов, беспроводной доступ в интернет, сертификаты на возобновляемую энергию («зеленые» сертификаты), лицензии на выбросы оксидов серы и азота, предметы искусства, антиквариат, дома, автомобили часто продаются с аукциона. Отдельные экономические операции, например недружественные поглощения, фактически являются аукционами (Там же). Аукционы к началу XXI в. могли бы исчезнуть с актуальной повестки дня экономической теории, если бы не получили серьезного импульса при масштабной приватизации в 1990-х гг. в посткоммунистических странах, развитии онлайн-торговли, продаже лицензий на использование спектра радиочастот, создании новых рынков (электроэнергии, услуг транспорта и т. д.), организации рекламного пространства (Maskin, 2004).

Во-вторых, отмечается всплеск интереса к наблюдательному и эксперименталь-

1 Дизайн рынков является успешным приложением теоретико-игровых моделей и идей к решению практических задач, связанных с размещением ресурсов (Самуэльсон, 2017). Это - разновидность экономической инженерии, которая использует лабораторные исследования, теорию игр, моделирование и др. Его вызовы вдохновляют экономистов переосмыслить основы классической экономической теории (Roth A.E. 2012. The Theory and Practice of Market Design: Prize Lecture. URL: https://www.nobelprize. org/uploads/2018/06/roth-lecture.pdf). Выделяют две области рыночного дизайна - рынки соответствий (или рынки без денег) и аукционные рынки. ному тестированию главных гипотез теории аукционов. Аукцион также является ценным полигоном для эмпирической проверки отдельных положений экономической теории (особенно теории игр с неполной информацией $)^{2}$.

В-третьих, поскольку основная трансакция аукциона - передача товара от продавца к покупателю в обмен на денежный платеж - является фундаментальной для всей экономики, теория аукционов тесно связана с другими теоретическими областями (Maskin, 2004). Она сыграла важную роль в развитии методов ценообразования и форматов переговоров, в ходе которых покупатели и продавцы активно участвуют в определении цен, способствовала совершенствованию техники анализа и дала дополнительный импульс к развитию теории монопольного и олигополистического ценообразования, используется в изучении неценовых методов распределения ограниченных ресурсов (очереди, нормирование, лоббистские сражения, войны на истощение, битвы за поглощение) (Klemperer, 1999).

Теория аукционов и смежные области экономического анализа не обделены вниманием Нобелевского комитета. В 1994 г. премию Шведского государственного банка памяти Альфреда Нобеля в области экономических наук получили Дж. Харсаньи, Дж. Нэш, Р. Зелтен за анализ равновесия в теории некооперативных игр. Работы этих исследователей явились основой для последующего развития теории аукционов. В 1996 г. Дж. Миррлис и У. Викри награждены за фундаментальный вклад в экономическую теорию стимулов в условиях асимметричной информации. Премия 2007 г. присуждена Л. Гурвичу, Э. Маскину и P. Майерсону за разработку основ теории

${ }^{2}$ Как отмечает Э. Рот, теория игр - это часть экономической теории, которая фокусирует внимание не только на стратегическом поведении людей в экономической среде, но и на проблемах распространения информации, влиянии ожиданий игроков на экономические решения, противоречиях между равновесием и эффективностью (Roth, 1991). Теория игр утвердилась в качестве одной из основ методологического индивидуализма и в современной экономической теории практически вытеснила общую теорию равновесия. Она является языком экономической науки и будет использоваться и развиваться в новых областях экономических исследований (Самуэльсон, 2017). 
дизайна механизмов 3 . На положениях этой теории частично основана теория дизайна рынка, разрабатывающая методологию создания рынков с определенными свойствами и включающая теорию соответствия и теорию аукционов. В 2012 г. Нобелевским комитетом отмечено исследование Э. Рота и Л. Шепли за вклад в теорию соответствия (поиска и подбора) и практику дизайна рынка ${ }^{4}$. И, наконец, в 2020 г. Нобелевский комитет отметил ученых, внесших значительный вклад в теорию аукционов и изобретение их новых форматов - лауреатами стали П. Милгром ${ }^{5}$ и Р. Уилсон ${ }^{6}$.

${ }^{3}$ Дискуссия между О. Ланге и Фр. Хайеком по поводу эффективности фундаментально различных экономических систем (капиталистической и социалистической) привела к развитию идеи, что экономические институты могут рассматриваться как механизмы коммуникации, обеспечивающие коллективное принятие решений (на основе учета индивидуальных стимулов) с целью повышения эффективности размещения производственных ресурсов. Проектирование механизмов с применением теории игр, благодаря работам Л. Гурвича, Э. Маскина, Р. Майерсона, стало процветающей областью экономической теории (Mechanism Design Theory: Scientific background on the Sveriges Riksbank Prize in Economic Sciences in Memory of Alfred Nobel 2007. URL: https://www.nobelprize.org/uploads/ 2018/06/advanced-economicsciences2007-1.pdf).

4 Этими учеными исследована важная экономическая проблема: как на рынках без денег наилучшим образом согласовать интересы разных агентов. Например, учеников необходимо распределить по школам, а доноров человеческих органов связать с пациентами, нуждающимися в трансплантации. Рот и Шепли попытались ответить на вопросы: как повысить эффективность таких согласований? Какие методы использовать в каждом конкретном случае?

${ }^{5}$ Американский экономист Пол Р. Милгром родился в Детройте 20 апреля 1948 г. Окончил математический факультет Мичиганского университета (1970), аспирантуру Стэнфордского университета, имеет докторскую степень по бизнесу (1979). Преподавал в школах менеджмента и на экономических факультетах университетов США: Северо-Западного (1979-1983), Йельского (1982-1987), Стэнфордского (с 1987 г. по настоящее время). Является старшим научным сотрудником Стэнфордского института исследований экономической политики. Член Национальной академии наук США, Американской академии искусств и наук, Эконометрического общества. Награжден премиями Эрвина П. Неммерса в области экономики (2008), Джона Дж. Карти за развитие науки (совместно с Д. Крепсом и Р. Уилсоном, 2018), Фонда BВVA в области экономики, финансов и менеджмента (2012). Является соучредителем и председателем совета директоров компании «Auctionomics». URL: https://milgrom.people. stanford.edu/; URL: https://www.gsb.stanford.edu/facultyresearch/faculty/paul-r-milgrom

${ }^{6}$ Американский экономист Роберт Б. Уилсон родился в г. Дженива, штат Небраска, 16 мая 1937 г. Окончил Гарвардский университет (1959), там же получил степень доктора делового администрирования (1963). С 1964 г. преподает в Стэнфордском университете (профессор с 1971 г.). Президент Эконометрического общества (1999). Почетный доктор права Чикагского университета (1995), почетный доктор экономики Норвежской школы экономики (1986) и Лондонской школы экономики (2018). Член
Стандартные (классические) форматы и основные модели аукционов. Аукционы различаются по двум основным параметрам: формату и информации ${ }^{7}$.

Формат определяет правила того, как участники торгов делают ставки, как объявляются и обновляются цены, как закрывается аукцион и устанавливается победитель. Изначально теория аукционов сравнивала стратегии и результаты торгов в четырех форматах: английский аукцион - предусматривает, что открытые заявки будут подаваться участниками в порядке возрастания от начальной цены (часто устанавливаемой продавцом) до тех пор, пока ни один из них не захочет поднимать ставку, при этом объект передается тому, кто предложил наивысшую цену, по этой же цене; закрытый аукцион второй цень - участники торгов подают закрытые заявки (например, в запечатанных конвертах), и тот, кто предложил самую высокую цену, побеждает и платит за товар цену, равную величине второй ставки; голландский аукцион - открытые торги начинаются с цены высокого уровня, установленной продавцом, которая постепенно снижается, пока какой-либо участник не примет и не заплатит эту цену; закрытый аукцион первой иены - каждый участник подает одну заявку, не наблюдаемую другими, и тот, кто предложил самую высокую цену, выигрывает и платит то, что предложил ${ }^{8}$.

Национальной академии наук США, Американской академии искусств и наук, Эконометрического общества. Награжден премиями Джона Дж. Карти за развитие науки (совместно с Д. Крепсом и П. Милгромом, 2018), Фонда BBVA в области экономики, финансов и менеджмента (2016). Р. Уилсон является научным руководителем докторских диссертаций трех нобелевских лауреатов - Р. Рота, Б. Хольмстрема (2016) и П. Милгрома. URL: http:// www.gsb.stanford.edu/users/rwilson

${ }^{7}$ Здесь и ниже используются: Improvements to Auction Theory and Inventions of New Auction Formats: Scientific Background on the Sveriges Riksbank Prize in Economic Sciences in Memory of Alfred Nobel 2020. URL: https://www. nobelprize.org/uploads/2020/09/advanced-economicsciencesprize 2020.pdf; The Quest for the Perfect Auction: Popular Science Background. URL: https://www.nobelprize.org/prizes/economicsciences/2020/popular-information/

8 Различные форматы аукционов применяются для продажи широкого спектра благ. Например, формат английского аукциона широко используется для торговли на онлайн-платформах (например, еВау). Аукционы второй цены с XIX в. употреблялись для продажи почтовых марок, в настоящее время они востребованы поисковыми системами в Интернете при торговле рекламными площадями. Как работает аукцион в системе размещения поиско- 
Сравнение различных форматов аукционов осуществляется по двум критериям. С точки зрения продавца естественным является критерий оптимальности - максимизация получаемого дохода (ожидаемой цены продажи). С позиций общества важна эффективность (объект должен оказаться в руках того, кто ценит его больше всех и, соответственно, будет эффективно использовать). Критерий эффективности может быть более важным, чем критерий оптимальности, особенно при организации аукционов по приватизации объектов государственной собственности (Myerson, 1981). В этом случае, возможно, правительство должно выбрать формат, обеспечивающий эффективное размещение ресурсов, даже если доход при использовании другого формата будет выше 9 .

Второй важнейший параметр, по которому различаются аукционы, - информащия участников о стоимости объекта продажи, которая включает как сигналы, недоступные для других (частные ценности), так и знания о свойствах объекта, влияющие на ценностную оценку всех участников (общие ценности). Поскольку участники торгов, как прави-

вой и тематической контекстной рекламы, подробно описано, например, на сайте Яндекс (URL: https://yandex.ru/ support/direct/technologies-and-services/vcg-auction.html). На цветочных аукционах в Нидерландах, полагающихся на формат голландского аукциона, за год продается более 6 млрд цветов. Аукционы первой цены являются обычным форматом для компаний и организаций при закупке товаров или услуг, а также для правительств при заключении государственных контрактов или распределении прав на добычу полезных ископаемых.

${ }^{9}$ Существует и иная точка зрения - эффективность не должна быть критерием выбора формата аукциона. Аргументируется это тем, что победитель торгов может всегда перепродать объект тому, для кого он более ценен. Этот подход критикуется по двум позициям: во-первых, в условиях несовершенной информации не существует механизма (даже теоретического), который обеспечил бы переход ранее приватизированного объекта от неэффективного собственника к эффективному; во-вторых, перепродажа обычно требует значительных трансакционных издержек и может не состояться вообще. Поэтому политикам, заинтересованным в повышении эффективности размещения ресурсов, следует тщательно выбирать формат аукциона именно при приватизации (Milgrom, 2004). Дилемму между эффективностью и доходом при проведении приватизационного аукциона первой или второй цены раскрывает простое наблюдение: если правительство устанавливает резервную цену выше частных ценностей всех участников торга, то объект не будет продан, и это - проявление неэффективности. К тому же покупатели не без оснований могут полагать, что объект в будущем будет выставлен на продажу уже с более низкой начальной ценой, и проявят пассивность в ходе первых аукционов (Krishna, 2010). ло, преследуют разные цели и действуют стратегически, поведение одного из них нельзя понимать отдельно от поведения других. И все же аукционы - это не игры с нулевой суммой. Напротив, смысл их состоит в том, чтобы создать как можно большую ценность, предоставив объект покупателю, который наилучшим образом использует его. Следовательно, строгий анализ аукционов был невозможен до тех пор, пока теория некооперативных игр не вышла за рамки частного случая игр с нулевой суммой. Этот шаг сделал в 1950 г. Дж. Нэш. Изучение реалистичных условий аукциона, в которых каждый участник имеет некоторую частную информацию, стало возможным после расширения теоретических основ, созданных Нэшем, в работах У. Викри и Дж. Харсаньи ${ }^{10}$.

Основные модели аукционов:

модель, полагающаяся на независимые частные ценности, - теоретически обоснована У. Викри и рассматривает частный случай, когда ожидаемая полезность от объекта, выраженная в деньгах, для одного участника аукциона не зависит от информации о ценности объекта для всех других участников (даже если их предпочтения станут известными $)^{11}$;

модель, основанная на общих иенностях, теоретически обоснована Р. Уилсоном и характеризует другой частный случай равновесных торгов, когда фактическая стоимость предназначенного для продажи объекта одинакова для всех участников аукциона, но они имеют разную предварительную информацию о ее величине (если бы стал возможен обмен информацией, то ценности всех были бы примерно одинаковыми);

гибридная модель, основанная на частных и общих иенностях, - предложена П. Милгромом и рассматривает общий случай взаимозависимых ценностей, когда фак-

10 Подходящей концепцией равновесия аукционов с несовершенной информацией является равновесие БайесаНэша: стратегия каждого игрока есть функция собственной информации, при этом ожидаемый выигрыш максимизируется с учетом стратегий других игроков и убеждений игрока относительно информации других игроков (Harsanyi, 1995; Vickrey, 1961).

${ }^{11}$ Предположение о независимых частных ценностях наиболее правдоподобно, когда ценность объекта для участника торгов определяется только его последующим потреблением (использованием). Но если ценность объекта связывается и с возможной ценой его перепродажи, это предположение не является удачным (Krishna, 2010). 
тическая стоимость предназначенного для продажи объекта одинакова для участников аукциона, информация одних влияет на частные ценности других, но эти ценности остаются различными.

Модель аукциона с частными ценностями Викри: теорема об эквивалентности доходов. До начала 1960-х гг. микроэкономическая теория неявно полагала, что конкретные правила (форматы), регулирующие сочетание предлагаемых покупателями и запрашиваемых продавцами цен, в конечном итоге не воздействуют на рыночные результаты (равновесные цены и эффективность размещения ресурсов). У. Викри одним из первых обосновал существенное влияние рыночных правил на цену и объем торговли. Он показал, что разработка новых форматов аукционов может содействовать росту эффективности рынка или достижению иных общественно значимых целей ${ }^{12}$. Его работы не только заложили основы экономической теории аукционов, но и были важны для понимания путей повышения эффективности размещения ресурсов в условиях несовершенной информации (например, для решения проблемы побуждения людей заявить об истинной готовности платить за общественные блага $)^{13}$.

Разработанный Викри дизайн аукциона второй цены, на котором продается единичный неделимый объект, предполагает, что частные оценки объекта участниками являются статистически независимыми случайными величинами (поэтому модель известна как модель независимых частных ценностей), а сами участники торгов нейтральны к риску и изначально симметричны (распределение ценностей одинаково для них).

Механизм аукциона второй цены выявляет истинную готовность человека платить. Каждый участник имеет доминирую-

${ }^{12}$ Milgrom P. 1996. Procuring Universal Service: Putting Auction Theory to Work: Lecture at the Royal Academy of Sciences. URL: https://www.nobelprize.org/uploads/2018/06/ vickrey_lecture_milgrom.pdf

13 Э. Маскин подчеркивает, что основное достоинство разработанного Викри формата аукциона заключается в том, что этот формат обеспечивает эффективное распределение ресурсов (Maskin, 2004). Сам Викри отмечает, что его исследование было вдохновлено идеей А. Лернера о том, что на рынках с несовершенной конкуренцией необходимо развивать институты, обеспечивающие такое же эффективное размещение ресурсов, как и в условиях совершенной конкуренции (Vickrey, 1961). щую стратегию - выбирает ставку, равную своей оценке стоимости объекта. Он выигрывает и получает положительную сумму, когда его оценка выше самой высокой конкурирующей ставки, и проигрывает, если его оценка ниже этой ставки. Аукцион второй цены распределяет товары общественно эффективным способом: объект переходит к участнику торгов с самой высокой частной ценностью, и он оплачивает социальные альтернативные издержки, равные второй по величине ставке (Vickrey, 1961).

Хотя аспект эффективности был главным для Викри, его интересовал и вопрос о том, какой из четырех классических форматов аукционов обеспечит наибольший ожидаемый доход (будет оптимальным) в условиях независимых частных ценностей. Им доказано, что голландский аукцион (аукцион по убыванию) и аукцион первой цены стратегически эквивалентны (для каждой стратегии на закрытом аукционе первой цены существует эквивалентная стратегия на голландском, и наоборот). Цена, при которой участник торгов планирует выйти из голландского аукциона, соответствует его оптимальной ставке на аукционе первой цены ${ }^{14}$. У этих форматов нет доминирующих стратегий, поскольку оптимальные ставки зависят от стратегий других участников. Понижение ставки увеличивает доход в случае выигрыша, но также повышает и вероятность проигрыша. Оптимальные ставки уравновешиваются этими двумя соображениями.

Закрытый аукцион второй цены и английский аукцион также эквивалентны ${ }^{15}$ : цена, по которой участник торгов планирует выбыть из английского аукциона, соответствует его частной ценности. На обоих аукционах побеждает участник с наивысшей оценкой и платит цену, равную второй по величине ставке. Их отличительной чертой

14 По сути, голландский аукцион, хотя и описывается как динамическая игра, статичен. Каждый участник для себя определяет цену, по которой готов купить объект, пока другие участники свои предпочтения еще не обозначили; тот, кто выбирает самую высокую цену, выигрывает и платит эту цену. Поэтому аукцион по убыванию иногда называют открытым аукционом первой цены (Klemperer, 1999).

15 Эквивалентность между английским аукционом и аукционом второй цены слаба: оптимальные стратегии в обоих случаях одинаковы, только если частные ценности являются независимыми. Как будет показано ниже, если ценности взаимозависимы, два аукциона не обязательно должны быть эквивалентными. 
является то, что они предполагают только индивидуальную рациональность, т. е. оптимальная ставка участника не зависит от его ожиданий в отношении других ставок ${ }^{16}$. Аукцион по возрастанию иногда называют открытым аукционом второй цены.

Анализ Викри показал, что если участники нейтральны к риску, а их оценки объекта статистически независимы и равномерно распределены по интервалу ${ }^{17}$, то (в равновесии по Нэшу) все форматы аукционов эффективны и оптимальны в модели, основанной на независимых частных оценках, - выставленный на продажу объект окажется в руках участника торгов, который ценит его больше всех, и продавец получит одинаковый ожидаемый доход $^{18}$. Этот результат известен как теорема об эквивалентности доходов ${ }^{19}$.

Викри не увязывал результаты своего исследования с традиционной теорией цен. Позднее Дж. Бюлоу и Д. Робертс значительно упростили анализ оптимальных аукционов, показав его равнозначность исследованию стандартной ценовой дискриминации третьей степени, т. е. микроэкономический анализ соотношения предельного дохода и предельных издержек может использоваться при изучении аукционов (Bulow, Roberts, 1989).

Теорема об эквивалентности дохода, на первый взгляд, подтверждает вывод неоклассиков о том, что рыночные цены и объемы продаж определяются именно факторами со стороны спроса и предложения, а не особенностями рыночного формата. Однако у Викри иное ее понимание: эффективность раз-

${ }^{16}$ Additional background material on the Bank of Sweden Prize in Economic Sciences in Memory of Alfred Nobel 1996. URL: https://www.nobelprize.org/prizes/economic-sciences/ 1996/advanced-information/

${ }^{17}$ Модель Викри имеет и другие допущения: отсутствует сговор между участниками торгов, они не испытывают влияния внешних эффектов от результатов аукциона и др.

${ }^{18}$ Р. Майерсон, Дж. Райли и У. Самуэльсон продолжили анализ проблемы оптимального аукциона. Они доказали, что в модели с независимыми частными ценностями каждый из четырех форматов является оптимальным в сочетании с тщательно подобранной резервной ценой (минимальная цена, установленная продавцом объекта, выставленного на аукцион) (Myerson, 1981; Riley, Samuelson, 1981).

19 Вывод об эквивалентности доходов говорит не о том, что все аукционы принесут один и тот же доход от продажи каждого объекта, а о том, что при проведении множества аукционов они обеспечивают в среднем одну и ту же цену продажи (Диксит, Скит, Рейли-младший, 2017). мещения ресурсов и максимизация выручки продавца могут быть обеспечены одновременно с помощью различных по дизайну аукционов, и это оставляет за их разработчиками свободу форматирования для достижения uньх задач. Так, доминирующие стратегии в дизайне аукциона второй цены (в отличие от других форматов) желательны и повышают вероятность эффективного результата, потому что устраняют стимулы для участников торгов тратить ресурсы на то, чтобы больше узнать о конкурентах ${ }^{20}$. И еще один научный результат данной теоремы нужно иметь в виду: она предоставляет теоретические основания для анализа доходности различных форматов аукционов, когда принятые при ее доказательстве допущения не выполняются (например, допущение нейтральности к риску заменяется допущениями склонности к риску или неприятия риска).

Когда участники торгов асимметричны, четыре формата, как правило, не могут быть ранжированы с точки зрения ожидаемого дохода ${ }^{21}$.

Модель аукциона с общими ценностями Р. Уилсона: «проклятие победителя». Предположение о независимых частных ценностях связывает стоимость объекта для каждого участника аукциона только с его собственной оценкой. Но чаще всего ценности взаимозависимы. В этом случае один участник может пересмотреть свою оценку, если получит информацию о ценностях других покупателей.

Уилсон был первым, кто создал основу для анализа аукционов с общими ценностями и описал, как участники торгов ведут себя в таких обстоятельствах. Его модель представляет частный случай, в котором стоимость объекта для всех участников одна и та же, но каждый из них не уверен в этом общем значении. Из-за такой неопределенности покупатели обусловливают свои ставки некоторой частной информацией, которая связана со стоимостью

${ }^{20}$ Milgrom P. 1996. Procuring Universal Service: Putting Auction Theory to Work: Lecture at the Royal Academy of Sciences. URL: https://www.nobelprize.org/uploads/2018/06/ vickrey_lecture_milgrom.pdf

${ }^{21}$ Additional background material on the Bank of Sweden Prize in Economic Sciences in Memory of Alfred Nobel 1996. URL: https://www.nobelprize.org/prizes/economic-sciences/ 1996/advanced-information/ 
объекта. Если эта частная информация различается, оценки объекта участниками аукциона также будут отличаться.

Уилсон рассмотрел аукцион на получение права на аренду вновь открытого нефтеносного участка земли, в связи с чем его модель иногда называют моделью прав на добычу полезных ископаемых (Wilson, 1969). Участок, выставленный на торги, имеет общую ценность (определяется запасами нефти) для всех участников, но они все не уверены в оценке того, сколько нефти там можно добыть. Каждый в частном порядке может нанять специалистов для проведения сейсмогеологических изысканий и получить ограниченную информацию о ценности аренды данного участка. Главный вывод Уилсона состоит в том, что победитель аукциона первой цены в модели с общими ценностями, вероятно, завысит истинную ценность объекта и будет находиться в худшем положении, чем те, кто проиграл аукцион. Чрезмерный оптимизм приведет к тому, что победитель может заплатить за объект больше, чем тот в действительности стоит ${ }^{22}$.

Систематическое завышение ставок по сравнению с их равновесным значением получило название эффекта «проклятия победителя» ${ }^{23}$. Поэтому рациональный участник должен сначала скорректировать свою оценку прибыли, предположив, что другие оценивают ее ниже, а он со своей ставкой в итоге победит, - и только после этого определить оптимальную ставку ${ }^{24}$. Он обязан проявить более сложное стратегическое мышление, чем предполагает модель аукциона с частными ценностями (Roth, Wilson, 2019).

Модель с общими ценностями мало что может дополнительно сказать об эффектив-

22 Предположим, что в аукционе первой цены участвуют несколько фирм с разными частными ценностями (равномерно распределенными), а общая ценность - это средняя величина этих частных оценок. Каждый участник увязывает свою ставку с частной ценностью: чем выше его оценка объекта, тем больше будет ставка. Победитель по окончании торгов узнает, что его ставка оказалась наивысшей, и это «плохая новость» для него, потому что ставка будет больше и общей ценности объекта.

${ }^{23}$ Насколько реальна такая опасность в действительности? Р. Талер собрал и проанализировал массу фактических данных, свидетельствующих о существовании «проклятия победителя». Он рассматривает его как доказательство нерационального поведения участников торгов, рыночную аномалию (Thaler, 1988).

24 Эффект «проклятия победителя» проявится по-иному, если одни участники имеют более полную информацию, ности размещения ресурсов при различных форматах аукциона - любой из них эффективен в том смысле, что объект всегда получает тот, кто ценит его выше всех.

Гибридная модель с частными и общими ценностями Милгрома. Большинство реальных аукционов по продаже одного объекта являются аукционами с частными и общими ценностями. Например, энергетическая компания, которая претендует на право добычи природного газа, обеспокоена как запасами газа в месторождении (общая ценность), так и стоимостью добычи (частная ценность, которая зависит от технологий, доступных для компании).

П. Милгром в работах начала 1980-х гг. развил теорию аукционов, изучая общий случай с частными и общими ценностями при правдоподобных (но поддающихся математической формализации) условиях несовершенной информации и распределения ценностей среди участников торгов. В совместной статье с Р. Вебером (Milgrom, Weber, 1982) он представил новые важные результаты исследования аукционов. Один из них касается того, как эффект «проклятия победителя» влияет на доходы продавца при использовании разных форматов аукционов. Элемент общих ценностей разрушает стратегическую эквивалентность между английским аукционом и аукционом второй цены. На английском аукционе аукционист начинает с низкой цены и повышает ее. Одни участники могут наблюдать цены, по которым другие покидают торги. Полученная дополнительная информация влияет на оценку ими стоимости объекта: они менее склонны предлагать цену ниже этой стоимости (менее опасаются «проклятия победителя»). Закры-

чем другие. Р. Уилсон анализирует проблему проведения закрытых конкурентных торгов в условиях асимметричной информации о ценности объекта. Ученого заинтересовал реальный случай проведения конкурентных торгов, описанный практиком Д. Вудсом. В закрытом аукционе первой цены на получение прав аренды нефтеносного участка участвовали две крупные нефтяные компании. Одна уже владела правами на прилегающий участок и, следовательно, путем бурения контрольных скважин на границе получила почти полную информацию о ценности объекта. Вторая компания собрала частичную и несовершенную информацию об объекте и, в конце концов, опасаясь эффекта «проклятия победителя», решила отказаться от участия в торгах (ценность игры для нее была равна нулю). Компания с полной информацией предложила цену ниже своей оценки (и ниже оптимальной) и выиграла (Wilson, 1967). 
тый аукцион второй цены такой возможности не предоставляет.

Напротив, голландский аукцион и закрытый аукцион первой цены в модели с общими ценностями сохраняют стратегическую эквивалентность. Голландский аукцион, где аукционист начинает с высокой цены и снижает ее до тех пор, пока кто-то не захочет купить объект, не генерирует никакой новой информации в процессе его проведения. В обоих форматах победитель узнает о том, что другие ставки ниже, чем его собственные, только по окончании торгов. Поэтому участники этих аукционов будут устанавливать цену значительно ниже, чем предполагаемая ими ценность объекта, чтобы не попасть под действие эффекта «проклятия победителя». Отсюда понятно, что английский аукцион приносит самый высокий ожидаемый доход, а аукцион второй цены - более высокий, чем голландский аукцион и аукцион первой цены.

Еще один важный вывод из этого анализа - дополнительная информация, полученная участниками в процессе аукциона, смягчит проявление эффекта «проклятия победителя» и, как следствие, будет способствовать росту активности торгов и повышению дохода продавца. Последнему рекомендуется предоставить участникам аукциона как можно больше информации о стоимости объекта еще до начала торгов (обнародовать сертификаты подлинности или протоколы проверки). Например, продавец дома может рассчитывать на более высокую окончательную цену, если покупатели имеют доступ к независимой экспертной оценке до начала аукциона.

Общий принцип, согласно которому ожидаемая цена повышается за счет ее лучшей привязки к частной информации участников торгов, известен как принцип связи. Определенный формат аукциона обеспечивает тем более высокий доход, чем сильнее такая связь (Milgrom, Weber, 1982; Klemperer, 1999).

То, что английский аукцион приносит больший доход, чем закрытый аукцион первой цены, кажется само собой разумеющимся $^{25}$. Однако это предполагает нейтральных к риску и симметричных участников торгов. Ранжирование в принципе может быть изменено, если покупатели не склонны к риску - в этом случае классические аукционы с точки зрения продавца не эквивалентны (Maskin, Riley, 1984).

Наблюдательная и экспериментальная проверка теории аукционов. С одной стороны, теоретические прогнозы о равновесных торгах и ценах при использовании определенных форматов открыли путь для эмпирического тестирования моделей на основе данных наблюдений, полученных с публичных аукционов. С другой стороны, в современной экономической теории для проверки прогнозов теории аукционов начали активно использоваться эксперименты.

В 1979 г. Р. Джонсон проанализировал аукционную практику Лесной службы США по продаже древесины для проверки теоремы об эквивалентности доходов и обнаружил более высокие доходы на аукционах с закрытыми торгами. Он объяснил это неконкурентным поведением участников открытых торгов. Р. Хансен проверил выводы Джонсона и пришел к заключению, что данные лесных аукционов все-таки не противоречат теореме об эквивалентности доходов (Hansen, 1986). В целом разница между доходами на закрытых и открытых аукционах оказалась не настолько большой, чтобы исключить случайность такого расхождения. Хансен считает, что руководители лесного хозяйства страны должны принять в качестве рабочей гипотезы утверждение, что любая модификация формата изменит стратегию торгов, но не уровень доходов государства от продажи древесины. Вероятная причина противоречивых результатов ранних тестов заключается в том, что рассматриваемые аукционы не удовлетворяли строгим информационным условиям теоретической модели с частными ценностями.

В конце 1980-х гг. К. Хендрикс и Р. Портер показали, что теоретические прогнозы модели с частными и общими ценностями подтверждаются эмпирическими исследованиями (Hendricks, Porter, 1988). Они изу-

25 У английского аукциона есть еще одно замечательное свойство: он может эффективно распределять товары даже с асимметричными участниками, если в ходе торгов они раскроют свою частную информацию - тогда победит тот, кто ценит товар больше всех (Maskin E.S. 1992. Auctions and Privatization: Symposium in Honor of Herbert Giersch. URL: https://scholar.harvard.edu/files/ maskin/files/auctions_and_privatization.pdf). 
чили практику федеральных аукционов по продаже прав на аренду дренажных вод на внешнем континентальном шельфе США с 1959 по 1969 г. Сдаваемые в аренду участки примыкали к участкам, на которых уже осуществлялась добыча нефти и газа. «Соседние» фирмы, которые владеют участками, примыкающими к выставленному на торги участку, были лучше «несоседних» фирм осведомлены о его арендной стоимости и меньше страдали от эффекта «проклятия победителя». Эти данные совпадают и с выводами Уилсона (Wilson, 1967).

В последние годы в эмпирических исследованиях был применен структурный подход, т. е. исследователи предполагали, что теория верна, и пытались вывести ненаблюдаемые функции ставок и распределения оценок на основе наблюдаемого поведения участников торгов.

Среди экспериментальных работ, тестирующих теорию аукционов, выделяются исследования Дж. Кагеля, Р. Харстада, Д. Левина. Например, они установили, что на аукционах с частными ценностями теорема об эквивалентности доходов не работает: ставки на аукционах первой цены выше, чем на голландских, а ставки на аукционах второй цены выше (даже часто превышают реальную ценность объекта продажи), чем на английских аукционах. Это несоответствие теоремы об эквивалентности доходов экспериментальным данным было объяснено эффектом режима (mode effect), когда аукционы с закрытыми предложениями сосредоточивают внимание участников на взаимосвязи цены и вероятности победы на торгах ${ }^{26}$, а открытые аукционы фокусируют внимание на прибыли, тем самым создавая небольшие, но постоянные различия в ставках. Известность получил и еще один экспериментальный результат: на аукционах с общими ценностями неопытные участники больше страдают от эффекта «проклятия победителя», поскольку опытные игроки в конечном итоге лучше реша-

26 Но наблюдения за интернет-аукционами зафиксировали прямо противоположные результаты: голландский аукцион обеспечивал доход на треть выше, чем закрытый аукцион первой цены. Эту аномалию тоже связывают с поведенческими особенностями участников торгов - они проявляли нетерпение в связи с чрезмерной продолжительностью аукциона (Диксит, Скит, Рейли-младший, 2017). ют проблему неблагоприятного отбора (Kagel, 1995).

Кагель и Левин экспериментально подтвердили закономерность, на которую обратил внимание Уилсон - чем больше участников аукциона, тем сильнее эффект «проклятия победителя». В больших группах испытуемые вели себя активнее и предлагали более высокие ставки (Kagel, Levin, 1986).

\section{II. Изобретение новых форматов аукционов}

К началу 1990-х гг. были обоснованы модели равновесных торгов для большинства форматов и информационных настроек аукционов одного объекта. Предсказания теории подтверждались эмпирическими исследованиями (на основе наблюдательных и экспериментальных данных). Центр теоретического анализа сместился с аукционов одного объекта на аукционы нескольких объектов. Этот сдвиг был определен расширением практики проектирования торгов для распределения электроэнергии, услуг общественного транспорта и других ограниченных ресурсов.

Но прежде всего потребность в изобретении новых форматов аукционов связана с революционными изменениями в сфере телекоммуникационных технологий и необходимостью эффективного перераспределения радиочастотного спектра. С одной стороны, появился новый спрос со стороны операторов мобильной связи и мобильного вещания на беспроводной доступ в Интернет, с другой - трансформировался спрос со стороны давно работающих на рынке телерадиостанций. Последнее обусловлено снижением популярности широкополосного аналогового вещания и развитием цифровых технологий, позволяющих передавать большее количество телевизионных каналов в определенном частотном диапазоне ${ }^{27}$. Альтернативой административному распределению и перераспределению лицензий на использование спектра могла стать их продажа на аукционах ${ }^{28}$.

${ }^{27}$ Milgrom P., Segal I. 2017. Designing the US Incentive Auction. Handbook of Spectrum Auction Design. Sydney: University of New South Wales. PP. 803-812.

${ }^{28}$ Еще в конце 1950-х гг. Р. Коуз отмечал необходимость использования рыночного механизма для распределения прав на радиочастоты. 
Общепризнан вклад Уилсона и Милгрома в разработку форматов таких аукционов. В своих работах они учитывали не всегда успешный практический опыт продажи спектра на аукционах в отдельных странах.

Распределение радиочастот в Новой Зеландии, Австралии и США в начале 1990-х гг. Правительством Новой Зеландии в 1990 г. были проведены первые аукционы по продаже радиочастот. На торги выставлялись национальные лицензионные права на ТВ-вещание. Каждая лицензия продавалась на однораундовом закрытом аукционе. Ставки участники должны были делать одновременно на все лоты, за которые собирались бороться, победители платили вторую по величине из предложенных цен. Результаты торгов в Новой Зеландии показали большой разрыв между первой ценой победителя и второй, которую он фактически заплатил (Milgrom, 1995). Для наблюдателей стало ясно, что участники оценивали лицензии намного дороже, чем фактически за них заплатили. Общий доход от аукционов, который специалисты прогнозировали в размере 250 млн, составил только 36 млн новозеландских долларов (McMillan, 1994). Основной ошибкой проведения данных аукционов был отказ от введения минимальных резервных цен. При небольшом количестве участников (как в Новой Зеландии) резервная цена заменяет отсутствующую конкуренцию на торгах ${ }^{29}$. Еще одна проблема, сопровождавшая проведение новозеландских аукционов по продаже лицензий на эфирный телевизионный спектр, - наблюдавшиеся искажения в мотивации участников, возникшие у них затруднения с решением вопроса о том, на какое количество лицензий претендовать и на скольких аукционах делать ставки (Milgrom, 1995).

В 1993 г. Австралия организовала продажу двух лицензий на услуги спутникового телевидения, и чтобы не повторять ошибок новозеландских коллег, правитель-

${ }^{29}$ И все же специалисты считают, что аукционы в Новой Зеландии сработали лучше альтернативных бюрократических процедур: предоставили радиочастотный спектр наиболее эффективным пользователям, сделали это быстро и с низкими административными затратами. Но доходов получено меньше, чем могло бы быть - аукционы не были оптимальными (McMillan, 1994). ство решило провести закрытые аукционы первой цены. Но их результаты также неприятно удивили организаторов - сделавшие самые высокие ставки компании отказались их выплачивать. Поскольку правительство не установило штрафные санкции, дефолт ничего не стоил победителям. В соответствии с правилами торгов лицензии должны были получить те, кто сделал следующие по величине ставки, но ими оказались те же компании - правила проведения аукционов разрешали участникам выставить ряд «каскадных» ставок. Ситуация отказа платить повторилась несколько раз. В конечном итоге эти аукционы задержали почти на год введение платного телевидения в Австралии (McMillan, 1994). Их изъян заключался в отсутствии резервной цены и штрафа за отказ победителя платить, а также в допущении делать «каскадные» ставки.

Ранний опыт продажи радиочастот показывает, насколько внимательно нужно подходить к разработке форматов аукционов, учитывать нюансы стратегического поведения игроков и особенности отрасли.

В США до тех пор, пока спрос на радиочастоты не превышал предложение, Федеральная комиссия по связи (FCC) выдавала различным компаниям лицензии на использование спектра, полагаясь на установленные административные процедуры. Такой способ распределения частот был основой для коррупции. С начала 1980-х гг., когда спрос существенно превысил предложение, частоты стали распределяться через розыгрыш лотереи, при этом победители имели право перепродавать полученные лицензии. В результате появился новый бизнес - создавались компании, единственной целью которых была подача заявок на участие в такой лотерее. Большинство победителей лотереи затем перепродавали полученные права на использование частоты с большой прибылью (Milgrom, 1995).

Назревшая проблема требовала решения, и FCC обратилась к экономистам-теоретикам, включая Милгрома и Уилсона, с просьбой разработать новый формат аукциона для продажи лицензий на использова- 
ние радиочастотного спектра. Были определены четкие требования к нему: а) «прозрачность» для участников; б) простые правила, понятные для неспециалистов; в) возможность быстро и с минимальными трансакционными издержками перераспределять частоты, учитывая технические сложности при использовании соседних частот (вероятность возникновения помех); г) раскрытие информации о ценности объекта продажи для участников аукциона.

С учетом сложности процесса перераспределения рынка частот FCC определила в качестве главных задач разработки дизайна аукциона не только максимизацию доходов от продаж, но и обеспечение эффективного использования полосы спектра, создание конкурентного рынка связи и недопущение монополизации спектра радиочастот, устранение возможности сговора и манипулирования аукционом ${ }^{30}$.

\section{Одновременный многораундовый аук-} цион. Для решения проблемы перераспределения радиочастот группа исследователей с участием Милгрома и Уилсона предложила новый формат одновременного многораундового аукциона (simultaneous multi-round auction), который позволяет участникам одновременно делать ставки на произвольное количество объектов в течение нескольких раундов. Функция многораундовости частично решает проблему «проклятия победителя», поскольку в ходе торгов участники получают информацию о частных ценностях друг друга - задействован принцип связи.

В каждом раунде все участники торгов повышают свои ставки на любой объект (или несколько объектов), который (кото-

${ }^{30}$ В теории для распределения нескольких объектов среди покупателей эффективным является аукцион Викри-Кларка-Гровса (VCG). Однако в процессе реализации такого формата потребовалось бы решить сложную в вычислительном отношении проблему поиска максимально выгодного распределения спектра с учетом множества ограничений в виде помех для смежных частот. К тому же при практическом использовании механизм VCG не обеспечит полной прозрачности (существует законодательная защита конфиденциальности заявок), что делает невозможным самостоятельную проверку участниками правильности выбора победителя торгов. И последнее - правила проведения аукциона VCG могут быть запутанными для небольших вещательных компаний, что заставит их отказаться от участия в нем и снизит уровень конкуренции (LeytonBrown, Milgrom, Segal, 2017). рые) они хотели бы купить. После закрытия раунда по каждому лоту определяются временные победители, при этом аукционист раскрывает информацию либо о всех сделанных ставках, либо о ставках победителей. Это позволяет участникам торгов уточнять стратегии назначения ставок и увеличивает вероятность того, что лицензии будут эффективно распределены. Функция аукциона с несколькими раундами означает, что количество раундов заранее не задано, и торги заканчиваются только тогда, когда избыточный спрос будет устранен по всем объектам. Участники выигрывают лоты, по которым предложили самые высокими ставки, и оплачивают эти ставки. Чтобы они не могли пассивно следить за другими предложениями, в форматирование аукциона было включено важное нововведение - «правило активности». Оно исключает возможность для участника пропускать раунд, не делая ставки (скрывать свой спрос, одновременно наблюдая за другими игроками и динамикой цен), а в последующем неожиданно ее поднять. Тем самым улучшается качество информации, сообщаемой на протяжении всего аукциона, и повышается его эффективность ${ }^{31}$.

Проведенный FCC в 1994 г. аукцион по продаже десяти лицензий на услуги узкополосной связи (для пейджинговой сети) принес 617 млн долл. США. Последующие аукционы в финансовом плане оказались более успешными: в марте 1995 г. были проданы 99 лицензий операторам сотовой связи на услуги широкополосного спектра за 7 млрд долл., а уже к середине 2009 г. американское казначейство получило доходы от продажи аналогичных лицензий на аукционах, равные 52,6 млрд долл. США ${ }^{32}$. Успех данного формата привлек внимание средств массовой информации и побудил правительства других стран проводить собственные торги по аналогичному формату.

Формат одновременного многораундового аукциона не лишен и недостатков. Он не позволяет формировать пакетные заявки, что приводит к неэффективному рас-

${ }^{31}$ URL: https://patents.justia.com/patent/20200349570

${ }^{32}$ Hazlett T.W. 2009. U.S. wireless license auctions: 19942009. URL: https://www.accc.gov.au/system/files/ Hazlett\%2C\%20Thomas\%20\%28Auctions\%20Paper\%29.pdf 
пределению спектра, когда участники торгов (случайно или из-за недобросовестных действий конкурентов) получают несмежные частоты диапазона в различных регионах. Существует опасность скрытого сговора участников о разделении частот спектра и снижении ставок в расчете получить «свои» частоты за меньшую цену.

Комбинаторные многораундовые аукционы. Формат комбинаторного аукциона (combinatorial clock auction) был разработан для устранения недостатков одновременного многораундового аукциона, прежде всего для решения проблемы пакетных заявок ${ }^{33}$. Впервые идея такого формата представлена на конференции FFC в 2003 г. ${ }^{34}$ (Ausubel, Cramton, Milgrom, 2006).

На практике комбинаторный аукцион разделен на несколько этапов. Первый этап (динамическая фаза аукциона) проходит в несколько раундов. В каждом раунде аукционист объявляет цены на отдельные объекты, а участники торгов отвечают ставками на какой-то один пакет объектов. Цены растут до тех пор, пока не исчезнет избыточный спрос по каждому объекту. В ходе второго этапа (закрытого аукциона) каждый участник может повысить свою ставку (в сравнении с установленной ранее) и заявить дополнительные ставки на другие пакеты объектов. На первых двух этапах все заявки являются пакетными по принципу «все или ничего». На третьем этапе компьютерная система решает «задачу определения победителя» ${ }^{35}$ : обрабатываются пакетные заявки всех участников, выбирается максимально эффективная ком-

33 Формирование пакетов должно учитывать, что частоты в одних и тех же диапазонах спектра часто являются объектами-субститутами, а на одинаковые полосы спектра в разных регионах - объектами-комплементами. Для эффективного размещения лицензий аукцион должен предоставить возможность участникам торгов оптимально комбинировать пакеты, что, например, позволит извлечь синергию от получения географически смежных лицензий (когда стоимость пакета объектов будет выше суммарной стоимости отдельных объектов).

${ }^{34} \mathrm{C}$ этого момента данный формат практически непрерывно эволюционировал (Ausubel, Baranov, 2014).

35 Л. Осубель и П. Милгром запатентовали изобретение на систему компьютерно-реализуемого аукциона, включающую связанные по сети с сервером аукциона компьютеры или терминалы аукциониста и участников торгов (System and method for a dynamic auction with package bidding. 2001. URL: https://patents.justia.com/patent/8566211). бинация распределения объектов между победителями и рассчитываются цены для каждого победившего в торгах с использованием правила второй цены (Ausubel, Baranov, 2014).

Есть несколько достоинств, отличающих комбинаторный аукцион от одновременных многораундовых торгов: он позволяет участникам размещать ставки на пакеты, снижает стимулы к сокращению спроса, не требует определения предварительных победителей в каждом раунде (после завершения раунда раскрывается только агрегированная информация о самых высоких ставках и избыточном спросе).

Но очевидны и слабые стороны этого аукциона: он является сложным и дорогостоящим при разработке и проведении; до завершения победители не знают, какой набор частот им достанется; он лучше работает с крупными пакетами; при большом количестве объектов (например, продажа спектра в странах с региональными лицензиями) участникам торгов сложно или невозможно точно выразить свои ценности для всех возможных комбинаций во втором раунде (Там же). Еще одна проблема связана с определением резервной цены ${ }^{36}$ : установление ее на слишком высоком уровне может спровоцировать отказ от участия, слишком низком - не позволит оптимизировать доходы продавца.

Формат комбинаторного аукциона впервые был реализован в Тринидад и Тобаго в 2005 г., затем использовался в США ${ }^{37}$ и Великобритании в 2008 г. В настоящее время применяется на рынке радиочастот в Австрии, Австралии, Дании, Канаде и других странах ${ }^{38}$ (Ausubel, Baranov, 2014).

${ }^{36}$ Резервные цены применяются на отдельные объекты или на пакеты объектов. Если они устанавливаются на пакеты, аукционист просто требует, чтобы оплата за каждую выигравшую заявку на пакет была не меньше, чем сумма резервных цен на объекты в пакете.

37 На комбинаторном аукционе беспроводного спектра в США в 2008 г. получено более 19 млрд долл. США (прежде всего от AT\&T и Verizon Communications). В ходе торгов было освобождено 25\% пространства УВЧ в диапазоне 700 МГц. URL: https://www.fcc.gov/auction/73

38 Комбинаторные аукционы в США и других странах сегодня проводятся в электронном виде и доступны через Интернет. Например, автоматизированная система аукционов FCC доступна любому, кто пользуется персональным компьютером с подключением к Интернету и браузером Netscape Navigator или Microsoft Internet Explorer. Система проста в использовании. 
Стимулирующий аукцион. Для перепрофилирования радиоспектра правительству часто приходится не просто реализовывать имеющиеся резервные радиочастотные диапазоны, но и выкупать их у старых владельцев, чтобы затем перепродать новым. Для этих целей (по запросу FFC) группа экономистов под руководством Милгрома разработала формат стимулирующего аукциона (incentive auction) для добровольного перепрофилирования спектра, когда владельцы лицензий отказываются от прав на них в обмен на долю в доходах от их продажи ${ }^{39}$.

Основная идея стимулирующего аукциона состоит в том, чтобы совместить одновременно три компонента: прямой аукиион, где определяются цены на лицензии беспроводной связи; обратный аукцион, формирующий цены, по которым телерадиокомпании добровольно откажутся от своих прав на использование спектра; процесс «переупаковки» (реорганизация и перевод на каналы в телевизионном диапазоне станций, которые продолжат работу после аукциона) для создания непрерывных блоков очищенного спектра широкополосной связи.

Стимулирующий аукцион может проходить в один или несколько этапов, каждый из которых состоит из обратного и прямого аукционов. Перед первым этапом определяется начальная цель очистки спекmpa (максимально возможная величина очищенного спектра с учетом выполнения требований по предельным помехам, которые могут создавать друг другу поставщики услуг беспроводной связи и телерадиоканалы). Затем запускается процесс торгов на обратном аукционе для определения общей суммы поощрительных выплат вещателям, необходимой для очистки спектра в соответствии с начальной целью.

Для всех владельцев лицензий в данном диапазоне устанавливаются начальные

${ }^{39}$ Milgrom P., Ausubel L., Levin J., Segal I. 2012. Incentive Auction Rules Option and Discussion. URL: https:// docs.fcc.gov/public/attachments/FCC-12-118A2.pdf

Л. Осубель, П. Крэмтон и П. Милгром получили патент на изобретение, в котором отражены отдельные идеи, реализованные в формате стимулирующего аукциона (System and method for the efficient clearing of spectrum encumbrances. 2014. URL: https://patents.justia.com/patent/8744924). цены по вариантам, которые они могут реализовать, - продажа лицензий или переход на более низкий диапазон и совместное использование канала. На основе этих цен собственники лицензий принимают решение об участии в обратном аукционе. Чтобы гарантировать, что все трансакции являются добровольными, всякий раз, когда цена на объект снижается, ее владельцу предоставлена возможность уйти с аукциона и затем пройти процесс «переупаковки» ${ }^{40}$. Чтобы обеспечить достижение цели переформатирования спектра, алгоритм обратного аукциона не должен предусматривать снижение цены до такого уровня, когда продавец примет решение о выходе и достижение цели аукциона станет технически невозможным. Чтобы убедиться, что результат возможен, аукцион определяет техническую осуществимость переназначения каналов всем участникам, которые собираются выйти либо не приняли участие в торгах. Эта проверка выполняется с помощью «средства проверки осуществимости» - программного обеспечения, которое устанавливает, может ли определенному набору станций быть назначен данный набор каналов таким образом, чтобы выполнялись миллионы ограничений по помехам. Разработка «средства проверки осуществимости» для работы с огромным набором данных - важнейшая задача создателей стимулирующего аукциона (Leyton-Brown, Milgrom, Segal, 2017).

Хотя участник обратного аукциона может не понимать всех расчетов, он обладает достаточной информацией ${ }^{41}$, чтобы сделать оптимальную ставку (знает, что выход необратим, цена лота может только снижаться и после любого ее снижения он может уйти с аукциона). Независимо от поведения других покупателей оптимальная стратегия участника обратного аукци-

${ }^{40}$ Milgrom P., Segal I. 2017. Designing the US Incentive Auction. Handbook of Spectrum Auction Design. Sydney: University of New South Wales. PP. 803-812.

41 Формат стимулирующего аукциона не требует, чтобы участники торгов сообщали или даже знали свои частные ценности. Во-первых, победителям нужно только убедиться, что они заинтересованы в продаже по окончательной цене. Во-вторых, в случае модели с общими ценностями обратная связь во время многораундных торгов помогает агрегировать информацию среди покупателей (Leyton-Brown, Milgrom, Segal, 2017). 
она состоит в том, чтобы покинуть торги только тогда, когда цена лота упадет ниже его частной ценности. Такой формат позволяет делать ставки на основании чистых стратегий и вести себя «правдиво» (Leyton-Brown, Milgrom, Segal, 2017).

Прямой аукцион в рамках каждого этапа следует за обратным аукционом. Торги на нем продолжатся до тех пор, пока выполняется правило заключительного этапа и существует избыточный спрос на лицензии. Правило заключительного этапа (набор условий, которые должны быть выполнены для закрытия стимулирующего аукциона по текущей цели очистки спектра) включает требования к величинам: средней цены лицензий на прямом аукционе (она должна быть не меньше определенной организатором резервной цены); выручки от прямых торгов, которая обязана покрывать все расходы по проведению стимулирующего аукциона (в том числе выплаты собственникам лицензий и возмещение телерадиоканалам расходов за «переупаковку»).

В случае невыполнения правила заключительного этапа будут проводиться дополнительные этапы с постепенно уменьшающимися целевыми значениями спектра на обратном аукционе и меньшим количеством спектра, доступным на прямом аукционе.

Важной задачей является сокращение времени проведения прямого аукциона, чтобы участники обратного аукциона не ждали его результатов в течение нескольких недель или месяцев. Для этого прямой аукцион имеет дополнительную функцию внутрираундовых торгов с установлением начальной и конечной цен раунда, что позволяет аукционисту повышать ставки с большим шагом и дает возможность самим участникам оптимизировать спрос на лоты. Проведение торгов на пакеты объектов, а не на отдельные частоты, также сокращает продолжительность прямого аукциона.

Кульминацией в разработке формата стимулирующего аукциона стало его практическое использование в США в 2016 г. В результате были перепрофилированы в диапазоне 600 МГц для мобильной широкополосной связи 70 МГц дорогостоящего и полностью чистого низкочастотного спек- тра. Дополнительно 14 МГц спектра очищены и остались непроданными. Компании беспроводной связи заплатили в общей сложности 19,768 млрд долл. США за приобретенный спектр, из этой суммы 10,054 млрд долл. США выплачено в качестве компенсации за отказ от права на вещание 175 телеканалам. Американское казначейство получило более 7 млрд долл. США, остальные средства были выплачены 957 радиотелеканалам в виде компенсаций за «переупаковку» ${ }^{42}$. Аукцион стал хорошим примером того, как достижения экономической теории и информатики могут быть объединены для создания новых рынков и роста общественного благосостояния (Leyton-Brown, Milgrom, Segal, 2017).

В 2002 г. Э. Рот в статье, которую посвятил своему научному руководителю Р. Уилсону, отметил, что в последние годы экономисты не только анализируют рынки, но и проектируют их. Дизайн рынка предполагает ответственность за детали, необходимость иметь дело со всеми сложностями рынка, а не только с его фундаментальными основами. Требуется инженерный подход, адаптирующий теоретикоигровые модели к решению практических задач ${ }^{43}$ (Roth, 2002). Огромный вклад в разработку такого подхода внесли П. Милгром и Р. Уилсон.

\section{СПИСОК ЛИТЕРАТУРЫ (REFERENCES)}

Диксит А., Скит С., Рейли-младший Д. 2017. Стратегические игры. Москва: Манн, Иванов и Фербер. [Dixit A., Skeath S., Reiley Jr. D. 2017. Games of Strategy. Moscow: Mann, Ivanov and Ferber. (In Russ.)]

${ }^{42}$ URL: https://auctiondata.fcc.gov/public/projects/ 1000; URL: https://docs.fcc.gov/public/attachments/DOC344397A1.docx

${ }^{43}$ П. Милгром является соучредителем коммерчески успешной консалтинговой фирмы «Auctionomics», которая разрабатывает новые форматы аукционов и программные продукты для их проведения. Клиенты «Auctionomics» органы государственного управления США (Министерство финансов, Федеральная комиссия по связи) и крупнейшие компании (Google, SaskTel, Yahoo, Micrisoft, Comcast, Vodafone и др.). 
Самуэльсон Л. 2017. Теория игр в экономической науке и не только. Вопросы экономики. № 5. C. 89-115. [Samuelson L. 2017. Game theory in economics and beyond. Voprosy ekonomiki. No 5. PP. 89-115. (In Russ.)]

Ausubel L.M., Baranov O.V. 2014. Market Design and the Evolution of the Combinatorial Clock Auction. American Economic Review. Vol. 104. No 5. PP. 446-451.

Ausubel L.M., Cramton P., Milgrom P. 2006. The Clock-proxy Auction: A Practical Combinatorial Auction Design. Combinatorial Auctions. Cambridge, MA: MIT Press. PP. 115-138.

Bulow J. I., Roberts D.J. 1989. The Simple Economics of Optimal Auctions. Journal of Political Economy. Vol. 97. No 5. PP. 1060-1090.

Hansen R.G. 1986. Sealed-bid versus open auctions: The evidence. Economic Inquiry. Vol. 24. No 1. PP. 125-142.

Harsanyi J.C. 1995. Games with Incomplete Information. American Economic Review. Vol. 85. No 3. PP. 291-303.

Hendricks K., Porter R.H. 1988. An Empirical Study of an Auction with Asymmetric Information. American Economic Review. Vol. 78. No 5. PP. 865-883.

Kagel J.H. 1995. Auctions: A Survey of Experimental Research. Handbook of Experimental Economics. Vol. 1. Princeton, NJ: Princeton University Press. PP. 501-585.

Kagel J.H., Levin D. 1986. The Winner's Curse and Public Information in Common Value Auctions. American Economic Review. Vol. 76. No 5. PP. 894-920.

Klemperer P.D. 1999. Auction Theory: A Guide to the Literature. Journal of Economic Surveys. Vol. 13. No 3. PP. 227-286.

Krishna V. 2010. Auction Theory. San Diego: Academic Press.

Leyton-Brown K., Milgrom P., Segal I. 2017. Economics and Computer Science of a Radio Spectrum Reallocation. Proceedings of the National Academy of Sciences. Vol. 114. No 28. PP. 7202-7209.

Maskin E. 2004. The Unity of Auction Theory: Milgrom's Masterclass. Journal of Economic Literature. Vol. 42. No 4. PP. 1102-1115.
Maskin E.S., Riley J.G. 1984. Optimal Auctions with Risk Averse Buyers. Econometrica. Vol. 52. No 6. PP. 1473-1518.

McMillan J. 1994. Selling Spectrum Rights. Journal of Economic Perspectives. Vol. 8. No 3. PP. 145-162.

Milgrom P. 1995. Auctioning the Radio Spectrum. Auction Theory for Privatization. Cambridge, England: Cambridge University Press.

Milgrom P. 2004. Putting Auction Theory to Work. Cambridge: Cambridge University Press.

Milgrom P., Weber R.J. 1982. A Theory of Auctions and Competitive Bidding. Econometrica. Vol. 50. No 5. PP. 1089-1122.

Myerson R.B. 1981. Optimal Auction Design. Mathematics of Operations Research. Vol. 6. No 1. PP. 58-73.

Riley J. G., Samuelson W.F. 1981. Optimal Auctions. American Economic Review. Vol. 71. No 3. PP. 381-392.

Roth A., Wilson R. 2019. How Market Design Emerged from Game Theory: A Mutual Interview. Journal of Economic Perspectives. Vol. 33. No 3. PP. 118-143.

Roth A.E. 1991. Game Theory as a Part of Empirical Economics. Economic Journal. Vol. 101. No 404. PP. 107-114.

Roth A.E. 2002. The Economist as Engineer: Game Theory, Experimentation, and Computation as Tools for Design Economics. Econometrica. Vol. 70. No 4. PP. 1341-1378.

Thaler R. 1988. Anomalies: The Winner's Curse. Journal of Economic Perspectives. Vol. 2. No 1. PP. 191-201.

Vickrey W. 1961. Counterspeculation, Auctions, and Competitive Sealed Tenders. Journal of Finance. Vol. 16. No 1. PP. 8-37.

Wilson R.B. 1967. Competitive bidding with asymmetrical information. Management Science. Vol. 13. No 11. PP. 816-820.

Wilson R.B. 1969. Competitive bidding with disparate information. Management Science. Vol. 15. No 7. PP. 446-448.

Wilson R.B. 1985. Efficient Trading. Contemporary Microeconomics and Welfare. London: Palgrave Macmillan. PP. 169-208. 
In citation: Belorusskiy Economicheskiy zhurnal. 2020. No 4. PP. 4-19. Belarusian Economic Journal. 2020. No 4. PP. 4-19.

\title{
THEORY AND APPLIED AUCTION FORMATS: A SHORT REVIEW
}

\author{
Victor Vorobiev ${ }^{1}$, Ihar Zhabianok ${ }^{1}$ \\ Authors affiliation: ${ }^{1}$ Belarusian State Economic University (Minsk, Belarus). \\ Corresponding author: Victor Vorobiev (vorobiev_v@bseu.by).
}

ABSTRACT. The article highlights Paul Milgrom and Robert Wilson's contribution to auction theory improving. It also outlines major theoretical auction models with a particular focus on the revenue equivalence theorem and a «winner's curse» effect. Thus, the number of challenges and achievements related to the development of new auction formats and their practical use is identified.

KEYWORDS: auction, private-values model, common-values model, private- and common-values model, simultaneous multi-round auction, combinatorial clock auction, incentive auction.

JEL-code: B21, D44, D47.

DOI: $10.46782 / 1818-4510-2020-4-4-19$

Received 17.11.2020 